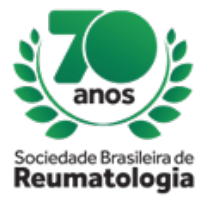

\title{
PRIMARY SJOGREN'S SYNDROME IN CHILDHOOD: REPORT OF THREE CASES
}

Filipe Augusto Carvalho Paula (UFMG, Belo Horizonte, MG, Brasil), Samara Quadros Lobê (UFMG, Belo Horizonte, MG, Brasil), Victória Carneiro Dal Moro (UFMG, Belo Horizonte, MG, Brasil), Maria Clara Cardoso Gomes Zampirolli (UFMG, Belo Horizonte, MG, Brasil), Leandro Augusto Tanure (UFMG, Belo Horizonte, MG, Brasil), Anna Carolina Faria Moreira Gomes Tavares (UFMG, Belo Horizonte, MG, Brasil), Flávia Patrícia Sena Teixeira Santos (UFMG, Belo Horizonte, MG, Brasil)

\section{BACKGROUND}

Primary Sjögren's syndrome (pSS) is a chronic inflammatory disorder with autoimmune epithelitis which determines glandular hypofunction. It's a systemic disease with diffuse organ impairment. The first case in childhood was described in 1960. Since it is difficult for this age group to report sicca syndrome, the challenge is the early diagnosis due to the prevention of complications and sequelae.

\section{CASE REPORT}

1- 12-year-old boy presented with no distinctive fever pattern, inflammatory arthralgia, thrombocytopenia, normochromic and normocytic anemia, high erythrocyte sedimentation rate (ESR) and C-reactive protein (CRP), hypergammaglobulinemia, hepatosplenomegaly. Infection, primary immunodeficiency, autoimmune lymphoproliferative syndrome (ALPS), and neoplasm were excluded. Positive ANA (1:160) nuclear fine speckled (NFS) with negative subtypes and normal levels of complements. Three years later, he presented with knees and writs arthritis and eye dryness (Break up time-fluorescein of 4). Salivary gland biopsy: focus score of 1 . After taking prednisone and methotrexate, there was a marked improvement of arthritis, fever, and haematological manifestations.

2- Female presenting thrombocytopenia since two months old. Referral from Haematology Outpatient Clinic when she was 7, because of positive ANA (1:640) NFS and anti-Ro (33; normal value $<7$ ). She evolved with reduced complement and elevated serum transaminase levels, high fever, wrists, and elbows arthritis. Infection, neoplasm, and autoimmune hepatitis were excluded. No sicca syndrome. Salivary gland biopsy: focus score of 1,2 . There was a complete resolution of arthritis and fever, and a partial resolution of thrombocytopenia after methotrexate and prednisone had been started. Liver biopsy is pending.

3- 15-year-old boy presented with repeated bilateral parotid swelling, since four years ago besides sicca syndrome. US: chronic sialadenitis. Positive ANA (1:640) NFS, high titers of anti-Ro and low titers of rheumatoid factor, anti-RNP and anti-Sm. Salivary gland biopsy: focus score of 4,3. Normal blood count.

\section{CONCLUSION}

The diagnosis of pSS in childhood is difficult due to lower prevalence or absence of dry symptoms. In literature, the main manifestation is parotid swelling, which was identified in only one case. Sicca syndrome symptoms can be late or absent, therefore it's not necessary to wait for them to suspect of pediatric pSS. Although classificatory criteria of a pediatric syndrome (Bartunkova, et al) is more accurate than those of ACR and EULAR, it has not yet been validated for clinical practice. According to Yokogawa, et al, the finding of any inflammatory lymphocytic infiltrate in minor salivary glands increases the diagnostic sensitivity. 